\title{
Theoretical analysis on ground vibration attenuation using sub-track asphalt layer in high-speed rails
}

\author{
Mingjing Fang ${ }^{1} \cdot$ Sergio Fernández Cerdas ${ }^{2,3}$
}

Received: 6 March 2015/Revised: 26 June 2015/ Accepted: 29 June 2015/Published online: 17 July 2015

(C) The Author(s) 2015. This article is published with open access at Springerlink.com

\begin{abstract}
Using a finite element method (FEM) program, a Portland cement concrete slab trackbed $\left(S_{0}\right)$, and a subtrack asphalt roadbed (RAC-S) were modeled under highspeed train loads to analyze their responses to ground vibration attenuation, by considering $10,15,20,25$, and 30 thick sub-track asphalt layer replaced on the top of the upper subgrade. FEM results show that the vibration amplitude of RAC-S is at least three times lower than the vibration for $S_{0}$. The maximum vibration amplitude of RAC-S is linearly increased with train speed. The vertical acceleration is found to be reduced by more than $10 \%$ when the asphalt layer thickness is increased from 10 to $20 \mathrm{~cm}$. However, the reduction in vertical acceleration is only about $1 \%$ when the thickness of the asphalt layer changes from 20 to $30 \mathrm{~cm}$. The vibration level is slightly lower if the asphalt layer has higher resilient modulus in the seasons of autumn or winter. This theoretical analysis indicates that a railway substructure that consists of a $10-20 \mathrm{~cm}$ thick high modulus asphalt layer located at the
\end{abstract}

Mingjing Fang

mingjingfang@whut.edu.cn

Sergio Fernández Cerdas

sefernandez@itcr.ac.cr; serfer26@gmail.com

1 Department of Road \& Bridge Engineering, School of Transportation, Wuhan University of Technology (WUT), 1040 Heping Ave, Wuchang District, Wuhan 430063, Hubei, People's Republic of China

2 Faculty of Costa Rica Institute of Technology, Cartago, Costa Rica

3 Costa Rican Building Research Center, Costa Rica Institute of Technology, 100 metros este, 10 metros sur y 500m este del Estadio Fello Meza, Cartago, Costa Rica top of trackbed shows a good performance in ground vibration control for high-speed rails.

Keywords High-speed railway · Substructure - Trackbed · Asphalt mix · Ground vibration attenuation · Mechanism analysis

\section{Introduction}

Vibration and noise induced by high-speed trains have adverse impact on buildings and residents along railway lines. Noise in essential is a certain form of vibration wave. Therefore, the noise reduction should be based on vibration control. According to previous researches [1-5], the environmental vibration induced by a train is complicated, depending on many factors such as the dynamic relation between car body and track mass, vibration spectrum, wheel-rail contact coupling, track-subgrade coupling, and structural resonance. However, according to the wave theory, the train-induced vibration undergoes generation (emission source), propagation (medium and ways of transmission), and receiving (receptor) [6, 7]. In each stage, there are many factors influencing the eventual vibration level. Nelson et al. [8] found that the key factors are roughness or friction between wheels and rails, discrete supports of track, dynamic characteristics of locomotive and rolling stock, stiffness of track support, track structure design, soil behavior, and building structure design. Intuitively, the noise generates when the vibration propagates in the air, and the ground vibration is mostly caused by wheel-rail impact and then, it propagates through soil.

Methods for controlling train-induced vibration can also be designed based on the three stages, generation, propagation, and receiving. Damping attenuation at the source is 
the basic measure and the elastic support in railway substructures absorbs the energy transferred due to ground vibration propagation. Also vibration attenuation measured at the receiving end could be used for improving or revising the structural design, such as setting elastic pads for sensitive devices. The friction damping caused by irregularity of wheel-rail contact area is one of the basic requirements for train operation, so that the train-induced vibration cannot be eliminated but only be reduced. Moreover, the noise attenuation equipment for the receiving end is usually too expensive to be extensively applied in railways. Therefore, researchers focus on the propagation stage to found reasonable control methods like medium-based isolation. Asphalt concrete (AC) with high strength and flexibility has been used in the railway substructure as the damping medium for vibration attenuation. In particular, rubber-modified asphalt concrete (RMC) as a material for high-speed train foundation has benefited in train-induced vibration reduction [9]. In addition, asphalt sub-track layer, also known as asphalt underlayment, is quite commonly used in Japan and western European countries for high-speed railway construction and in the United States for track rehabilitation and maintenance [10]. However, the effect and performance of an AC sub-track layer as a mean for vibration attenuation needs to be evaluated using quantitative indicators [11].

In this work, we adopted a finite element method (FEM) program, ABAQUS for modeling two trackbeds, one with a conventional slab and another with asphalt ballastless trackbed to evaluate the performance of sub-track asphalt layer as a wave propagation mean under dynamic loads. The vertical acceleration at the top of the lower subgrade layer was used to indicate the vibration intensity. Three variables of two models including train speed, asphalt layer thickness, and resilient modulus were compared to assess substructure performance as a ground vibration attenuator.

\section{FEM models of trackbeds}

\subsection{Geometric dimensions}

The modeling dimensions were designed based on the provisional design specification currently used in China [12]. Figure 1 shows the standard cross section for a conventional slab track $\left(S_{0}\right)$ and the location of sub-track asphalt layer of RAC-S as well as the 3D model after mesh. Based on $S_{0}$ cross section, we replace part of the upper subgrade layer with a $25 \mathrm{~mm}$ nominal maximum size (NMAS) dense-graded asphalt layer by considering five thicknesses of 10,15,20,25, and 30. This model is named as RAC-S. In addition, all modeling were created in three dimensions with $15 \mathrm{~m}$ in longitudinal direction in order to simulate longitudinal and transversal deformation of the track.

\subsection{Materials parameters}

A $25 \mathrm{~mm}$ NMAS asphalt mixture composed by a \#70 asphalt binder in terms of penetration performance grade which is a kind of asphalt commonly used in China and an aggregate gradation range shown in Table 1 [10] was considered for the FEM modeling. For simplification of analysis, all materials except the sub-track asphalt mix were analyzed using linear elastic constitutive relationship. According to Ref. [5], the material gradation parameters for linear elastic analysis were defined in Table 2. It is noted that the vertical stiffness, the transversal stiffness, and damping were $70 \mathrm{~km} / \mathrm{mm}, 60 \mathrm{~km} \mathrm{~s} / \mathrm{m}$, and $30 \mathrm{~km} / \mathrm{mm}$, $50 \mathrm{~km} \mathrm{~s} / \mathrm{m}$, respectively.

The asphalt mix material was analyzed on the basis of linear visco-elastic properties, which can be defined in terms of time or frequency domain. Either in time domain or in frequency domain, the calculations use the parameters fitted by a Prony series model. These parameters can be obtained by the tests of direct tension, relaxation, or creep. The linear visco-elastic behavior of asphalt material was defined by adopting Prony series for describing creep compliance and relaxation modulus curves [13]. The Prony series for the definition of visco-elastic properties can be expressed as,

$g(t)=1-\sum_{i=0}^{n-1} g_{i}\left(1-\mathrm{e}^{-t / \tau_{i}}\right)$

where $g(t)=E(t) / E_{0}=E(t) / E(0)$ is the normalized relaxation modulus of elasticity; $t$ is the creep time; $n$ is the terms of Prony series; $g_{\mathrm{i}}$ and $\tau_{i}$ are constants which express shear relaxation modulus and related time, respectively. By nonlinear fitting for $g(t)$ curves, the parameters of Prony series can be directly used for modeling the visco-elastic properties of asphalt concrete. This modeling is based on the analysis of creep tests, and using the shear relaxation modulus, $g_{i}$ and relaxation time $i$, from Refs. [14, 15].

In the FEM, eight nodes reduced integrated element, C3D8R, was used to mesh the structure for relatively high accuracy of displacement solution and low calculation time. The data extraction point is located on the top of the upper subgrade layer beneath one side of the rails. All finite element parts in models were simulated by solid element. Spring/dashpots were adopted for simulating the contact between rails and sleepers.

A $15 \mathrm{~cm}$ asphalt layer thickness $(h)$ and a $4,000 \mathrm{MPa}$ resilient modulus $(E)$, were used for evaluating the effect of the train speed $(v)$ on substructure performance due to dynamic load vibration. By setting $v=200 \mathrm{~km} / \mathrm{h}$ and 


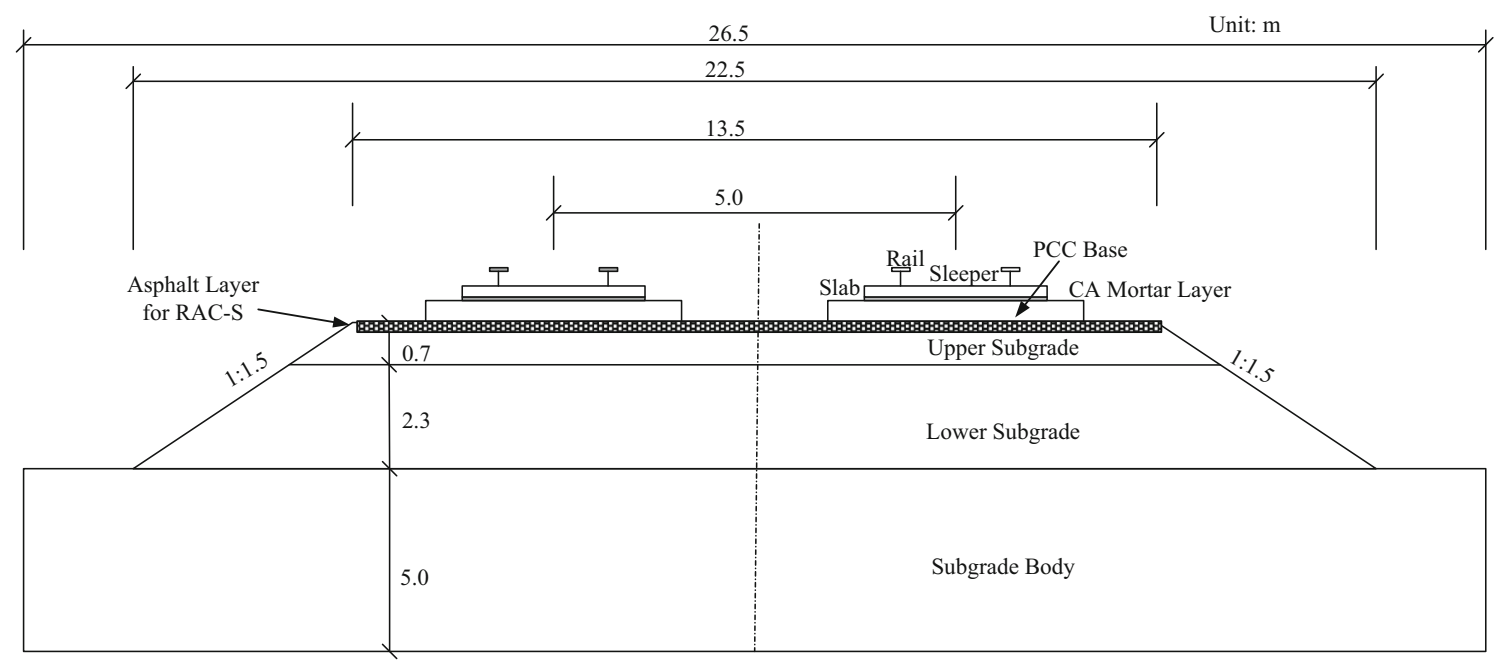

(a)

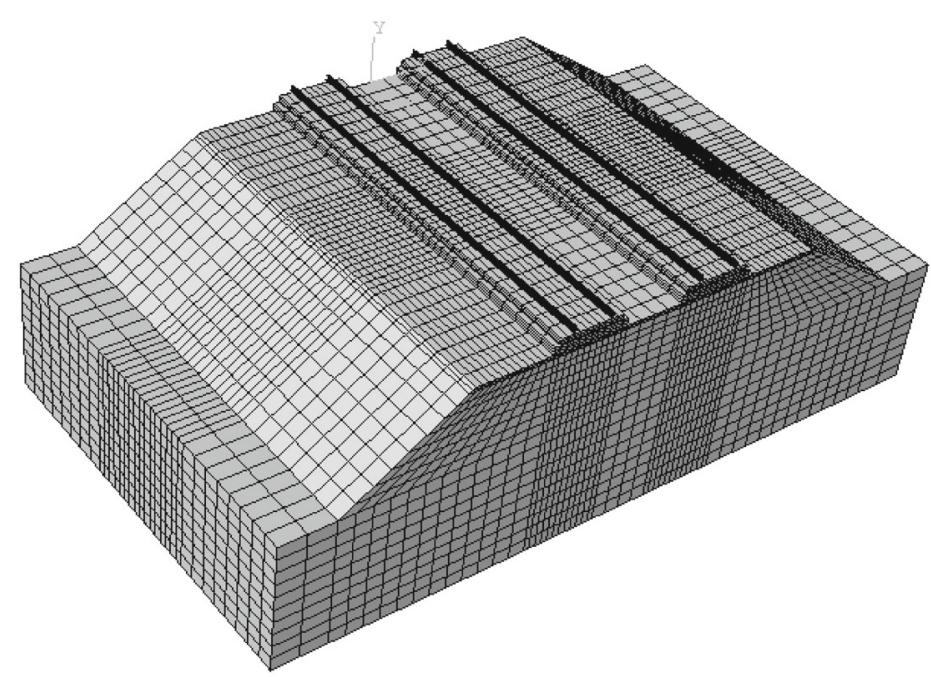

(b)

Fig. 1 Geometric dimensions and 3D model after mesh. a Full-cross section of referential slab trackbed model $S_{0}$ and location of sub-track asphalt layer for RAC-S. b 3D meshing model with $15 \mathrm{~m}$ in longitudinal length

Table 1 Gradation range of sub-track asphalt mix [10]

\begin{tabular}{llllllll}
\hline Size $(\mathrm{mm})$ & 37.5 & 26.5 & 19 & 16 & 13.2 & 9.5 & 4.75 \\
Passing (\%) & 100 & $90-100$ & $78-95$ & $67-87$ & $56-80$ & $42-68$ & $29-57$ \\
Size (mm) & 2.36 & 1.18 & 0.6 & 0.3 & 0.15 & 0.075 & $<0.075$ \\
Passing (\%) & $19-45$ & $14-34$ & $10-25$ & $5-17$ & $3-10$ & $1-7$ & - \\
\hline
\end{tabular}

$h=15 \mathrm{~cm}$, the effect of the average seasonal moduli of the asphalt layer with $E=4,812 \mathrm{MPa}$ (in spring), 2,562 $\mathrm{MPa}$ (in summer), 8,618 $\mathrm{MPa}$ (in autumn), and $15,715 \mathrm{MPa}$ (in winter) [16], was studied In this work, the modulus value of 4,000 $\mathrm{MPa}$ is reasonable for comparative calculation at normal temperature. In addition, the Poisson's ratio and density of asphalt mix were taken as 0.35 $\left(25^{\circ} \mathrm{C}\right)$ and $2,400 \mathrm{~kg} / \mathrm{m}^{3}$ [17]. 
Table 2 Materials parameters for FEM modeling (linear elastic relationship layers) [5]

\begin{tabular}{llllll}
\hline Parts & Density $\left(\mathrm{kg} / \mathrm{m}^{3}\right)$ & Elastic modulus $(\mathrm{Pa})$ & Poisson's ratio & Stiffness damping & Specific materials \\
\hline Rails & 7,830 & $2.06 \times 10^{11}$ & 0.300 & 0.015 & Steel \\
Track slab & 2,450 & $3.50 \times 10^{10}$ & 0.167 & 0.030 & C50, cement concrete \\
CA sand mortar & 2,050 & $4.00 \times 10^{8}$ & 0.167 & 0.035 & Cement, asphalt emulsion, sand \\
Concrete base & 2,300 & $3.30 \times 10^{10}$ & 0.167 & 0.030 & C40, cement concrete \\
Top layer of roadbed & 2,200 & $1.50 \times 10^{8}$ & 0.250 & 0.045 & Crushed stone \\
Bottom layer of roadbed & 2,000 & $0.60 \times 10^{8}$ & 0.250 & 0.039 & A, B filler, improved soils \\
Subgrade body & 1,800 & $0.50 \times 10^{8}$ & 0.330 & 0.035 & A, B, C filler, improved soils \\
\hline
\end{tabular}

\subsection{Modeling of train load}

The ellipse contact area of wheel-rail loading was simplified as a rectangle, and the exciting load model was adopted for simulating the dynamic loading of the train $[18,19]$. Each line was subjected to a set of wheel loading. The train load can be expressed as,

$F(t)=P_{0}+P_{1} \sin \omega_{1} t+P_{2} \sin \omega_{2} t+P_{3} \sin \omega_{3} t$,

where $P_{0}$ is the unilateral static wheel load; $P_{1}, P_{2}, P_{3}$ are the vibration loads computed by three control conditions, train stationary (I), dynamic additional load (II), and corrugations (III), respectively. If the unsprung weight of the train is $M_{0}$, the related amplitude of vibration load is,

$P_{1}=M_{0} \alpha_{i} \omega_{i}^{2}$,

where $\alpha_{i}$ and $\omega_{i}$ are the vector height and the circular frequency of vibration wavelength corresponding to three control conditions, respectively, and,

$\omega_{i}=2 \pi v / L_{i}$,

where $v$ is the train speed; and $L_{i}$ is the corresponding vibration wavelength. Because the dynamic additional load (II) and the corrugation effect (III) are not the focus of this work, the train load in this model can be modified as,

$F(t)=P_{0}+P_{1} \sin \omega t$,

$P(t)=F(t) / A=\left(P_{0}+P_{1} \sin \omega t\right) / A$,

where $A$ is the loading area. Based on Eq. (6), for the highspeed cars [13], $P_{0}=125 \mathrm{kN}, M_{0}=750 \mathrm{~kg}, a=0.4 \mathrm{~mm}$, $A=940 \mathrm{~mm}^{2}, L=2 \mathrm{~m}$. If $v=200,250,300,400(\mathrm{~km} / \mathrm{h})$, then $\omega=174.533,218.166,261.799,349.06(\mathrm{~Hz})$, respectively, and then $P_{1}=9.139,14.279,20.562,36.554$ $(\mathrm{kN})$, respectively.

\section{FEM models verification}

Because the model RAC-S was based on model $S_{0}$, it is reasonable that the numerical verification of $S_{0}$ is also performed before comparing ground vibration levels for

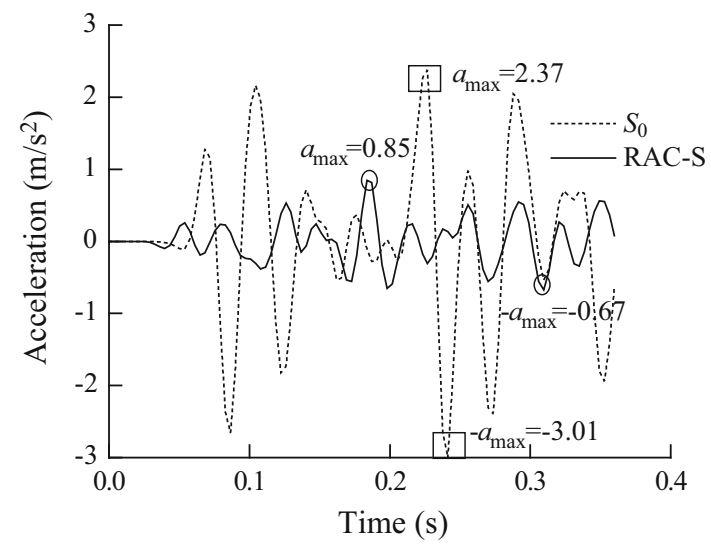

Fig. 2 Time-history curves of vibration acceleration for RAC-S and $S_{0}$

both models. As shown in Fig. 2, the time-history curves of vibration acceleration for RAC-S and $S_{0}$ show that the acceleration amplitude of model $S_{0}$ was about $-3.01 /$ $+2.37 \mathrm{~m} / \mathrm{s}^{2}$. From Ref. [20], the expected maximum vertical accelerations at similar position for $S_{0}$ substructures are in the range of 1.99 to $5.13 \mathrm{~m} / \mathrm{s}^{2}$, indicating that both RAC-S and $S_{0}$ models are reliable for the comparative study. In addition, the vibration amplitude of RAC-S was only about $-0.67 /+0.85 \mathrm{~m} / \mathrm{s}^{2}$. The ground vibration of RAC-S is approximately $70 \%$ lower than that of $S_{0}$, which means that the railway substructures with the asphalt layer have better capacity in ground vibration attenuation than the conventional concrete slab track.

\section{Performance analysis of vibration attenuation}

\subsection{Effect of train speeds}

From the time-history curves of acceleration at four different train speeds, as shown in Fig. 3, the maximum absolute vibration accelerations of RAC-S are $0.767 \mathrm{~m} / \mathrm{s}^{2}$ $(v=200 \mathrm{~km} / \mathrm{h}), 0.847 \mathrm{~m} / \mathrm{s}^{2} \quad(v=250 \mathrm{~km} / \mathrm{h}), 0.929 \mathrm{~m} / \mathrm{s}^{2}$ $(v=300 \mathrm{~km} / \mathrm{h}), 1.069 \mathrm{~m} / \mathrm{s}^{2}(v=400 \mathrm{~km} / \mathrm{h})$. The results show that when the train speed reaches $400 \mathrm{~km} / \mathrm{h}$, the 


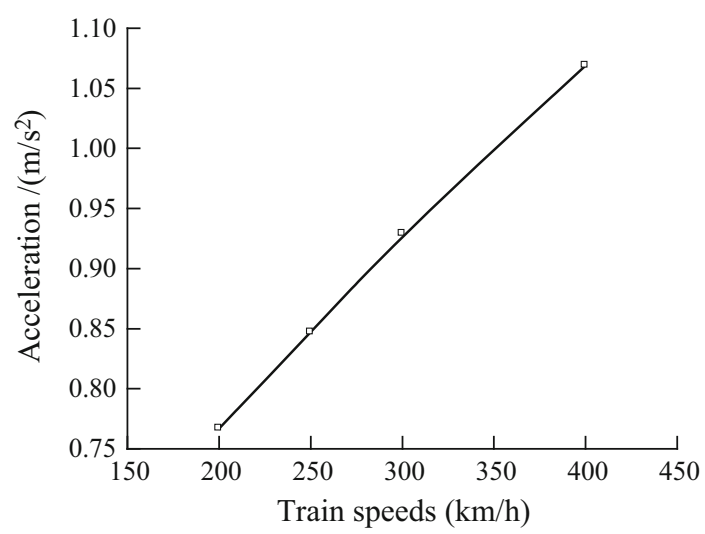

Fig. 3 Maximum accelerations at different train speeds

resulting acceleration is higher than the other three train speeds. From the comparison of absolute acceleration, the maximum acceleration increases from 0.767 to $0.926 \mathrm{~m} / \mathrm{s}^{2}$ when the train speed increases from 200 to $300 \mathrm{~km} / \mathrm{h}$. This indicates that the ground vibration linearly increases with train speed.

\subsection{Effect of the asphalt layer thicknesses}

Figure 4 shows the time-history curves of vertical acceleration, the maximum absolute acceleration was determined for five different asphalt layer thicknesses (see Fig. 4).

Figure 4 shows that the asphalt layer with a thickness of $10 \mathrm{~cm}$ has the maximum values of acceleration. The amplitude of vertical acceleration decreases as the asphalt layer thickness increases. Specifically, the asphalt layer thicknesses of 10 and $20 \mathrm{~cm}$ reported the maximum acceleration values $\left(0.864\right.$ and $0.770 \mathrm{~m} / \mathrm{s}^{2}$, respectively), with an amplitude difference of over $10 \%$. However, if the thickness is increased from 20 to $30 \mathrm{~cm}$, the acceleration is

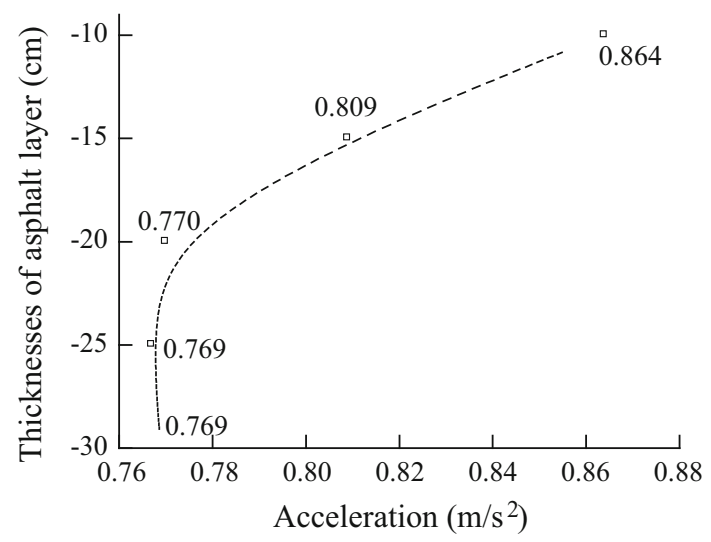

Fig. 4 Maximum accelerations with five thicknesses of asphalt layers (Note $y$-axis denotes distance beneath surface, and the zero level is located on the surface of the asphalt layer)

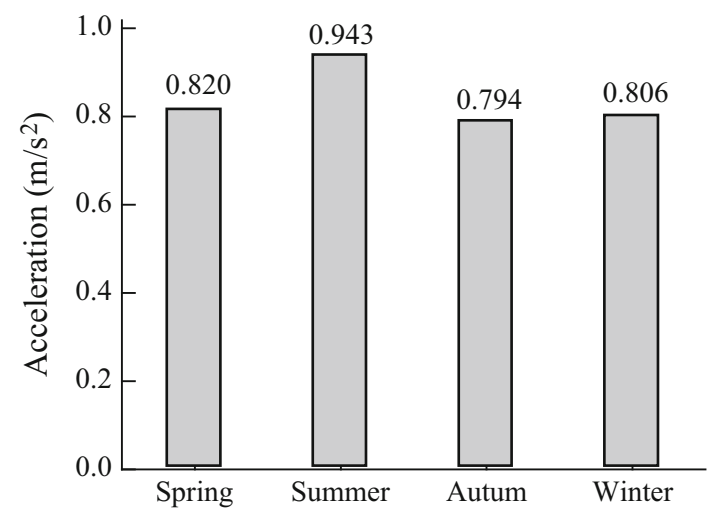

Fig. 5 Maximum accelerations with different modulus

only decreased to $0.769 \mathrm{~m} / \mathrm{s}^{2}$ with an amplitude difference of about $1 \%$. This shows that asphalt layer thickness of more than $20 \mathrm{~cm}$ does not result in an improvement in train-induced ground vibrations.

\subsection{Effect of substructure stiffness}

From the time-history curves with four different resilient moduli of the asphalt layer, the maximum absolute accelerations are shown in Fig. 5, which indicates that the vibration acceleration level in summer is higher than that in spring, autumn, or winter. This indicates that high asphalt modulus during autumn and winter can have a positive effect on ground vibration attenuation for railway trackbed and that high HMA deformation levels during summer can cause a significant reduction. The higher resilient modulus of asphalt layer in railway substructures is beneficial for the attenuation of train-induced ground vibration. However, it is important to consider the seasonal gain/reduction of HMA stiffness in the vibration attenuation. In high-temperature season like summer, the maximum vertical acceleration on subgrade surfaces is larger because of the lower modulus of sub-track asphalt layer.

The analysis above indicates that the asphalt railway substructure, which can perform well as foundation damping, has better performance in ground vibration attenuation than the conventional concrete slab tracks. The asphalt layer in the substructure is also beneficial for the long-term performance of rail substructures.

\section{Conclusions and suggestions}

A theoretical analysis of ground vibration attenuation using an asphalt sub-track layer was conducted using a FEM program. Based on the results, the main conclusions and suggestions are summarized as: 
- The ground vibration level is lowered using a sub-track asphalt layer, which linearly depends on train speeds.

- An increase of asphalt layer thickness results in a decrease of the vibration level. The decrease in amplitude is more than $10 \%$ when the thickness of asphalt layer is increased from 10 to $20 \mathrm{~cm}$; however, the decrease is only about $1 \%$ if the asphalt layer is increased from 20 to $30 \mathrm{~cm}$ in depth. Based on this, sub-track asphalt layers thicker than $20 \mathrm{~cm}$ may not be cost-effective.

- The resilient modulus of the asphalt layer plays an important role in lowering the vibration level. The lowering performance is better when resilient modulus of railway asphalt layer during seasons in autumn and winter than in spring and summer. This means high modulus asphalt mix is strongly suggested to be used.

In summary, asphalt mixtures used as sub-track layer can be beneficial for the attenuation of ground vibration in high-speed railways. Moreover, it is also very necessary to investigate the performances of different HMA materials such as dense and coarse graded, extra-high strength even high modulus, different binder grades, different modified binders, etc., which are the hot topics for future research on asphalt railway substructures.

Acknowledgments This research was jointly supported by National Natural Science Foundation of China (No. 51308429) and the Fundamental Research Funds for the Central University (WUT: 2013-IV067) and Opening Funds for Highway Engineering Key Laboratory of Sichuan Province (No. LHTE004201304). Additionally, we authors appreciate Dr. Mary Robbins, research faculty of National Center for Asphalt Technology (NCAT) at Auburn University in US, for her efforts in revising this paper. In addition, the anonymous reviewers should be appreciated very much for manly helpful suggestions and encouraged comments.

Open Access This article is distributed under the terms of the Creative Commons Attribution 4.0 International License (http://creativecommons.org/licenses/by/4.0/), which permits unrestricted use, distribution, and reproduction in any medium, provided you give appropriate credit to the original author(s) and the source, provide a link to the Creative Commons license, and indicate if changes were made.

\section{References}

1. Kaynia A, Madshus C, Zackrisson P (2000) Ground vibration from high-speed trains: prediction and countermeasure. J Geotech Geoenviron Eng 126:531-537
2. Takemiya H (2001) Simulation of track-ground vibrations due to high-speed trains. In: Proceedings of the 8th international congress on S. and V., Hong Kong, pp 2875-2882

3. Lai C, Callerio A, Faccioli E et al (2000) Mathematical modelling of railway-induced ground vibrations. In: Proceedings of the international workshop wave 2000, Bochum, pp 99-110

4. Sheng X, Jones C, Thompson D (2004) A theoretical model for ground vibration from trains generated by vertical track irregularities. J Sound Vib 272(3-5):937-965

5. Sheng X, Jones C, Thompson D (2004) A theoretical study on the influence of the track on train-induced ground vibration. J Sound Vib 272:909-936

6. Huang H, Yang Y (2001) A review of researches on groundborne vibrations with emphasis on those induced by trains. Proc Natl Sci Counc Repub China A 25(1):1-16

7. Fang M, Qiu Y, Ai C et al (2010) Review of vibration attenuation and noise control from railways. In: Proceedings of the 7th world congress on high speed rail. China Railway Press, Beijing, pp 33-41

8. Nelson JT, Saurenman HJ (1983) State-of-the art review: prediction and control of ground-borne noise and vibration from rail transit trains. Report Number UMTA-MA-06-0049-83-4

9. Wang J, Zeng X (2004) Numerical simulation of vibration attenuation of high-speed train foundations with varied trackbed underlayment materials. J Vib Control 10(8):1123-1136

10. Fang M (2012) Structural behavior and mix design for asphalt concrete substructures in high-speed rail. Ph.D. Dissertation of Southwest Jiaotong University, Chengdu

11. Ferreira P, Lopez-Pita A (2015) Numerical modelling of high speed train/track system for the reduction of vibration levels and maintenance needs of railway tracks. Constr Build Mater 79:14-21

12. Ministry of Railway (2005). The provisional design specification for new construction with speed of $200-250 \mathrm{~km} / \mathrm{h}$ for China's high-speed railway. TJS [2005] No. 140, China Railway Press, Beijing

13. Hibbitt, Karlsson, Sorensen, inc. (2010) ABAQUS/standard user's manual, ABAQUS/CAE user's manual, ABAQUS keywords manual, ABAQUS theory manual. HKS Inc, Dallas

14. Kim J, Lee H, Kim N (2010) Determination of shear and bulk moduli of viscoelastic solids from the indirect tension creep test. J Eng Mech 136(9):1067-1075

15. Kim J, Sholar G, Kim S (2008) Determination of accurate creep compliance and relaxation modulus at a single temperature for viscoelastic solids. J Mater Civ Eng 20(2):147-156

16. Rose J, Bei S (2004) Comparisons of railroad track and substructure computer model predictive stress values and in situ stress measurements. In: Proceedings of the AREMA, 2004 annual conference \& exposition, Nashville

17. Huang Y (2004) Pavement analysis and design, 2nd edn. Pearson Prentice Hall Inc, New Jersey

18. Jenkins $\mathrm{H}$ et al (1974) The effect of track and vehicle parameters on wheel/rail vertical dynamic forces. Railw Eng J 3(1):2-16

19. Liang B, Luo H, Sun C (2006) Simulated study on vibration load of high speed railway. J China Railw Soc 28(4):89-94

20. Shi X, Xuan Y, Wang L (2008) Simulation research on the dynamics characteristic of slab ballastless track structure on soil subgrade. China Railw Sci 29(4):15-20 